\title{
NEOLOGISMOS INCORPORADOS POR SALVÁ EN EL NUEVO DICCIONARIO DE LA LENGUA CASTELLANA'
}

\author{
DOLORES AZORÍN FeRnÁndeZ \\ Universidad de Alicante \\ dolores.azorin@ua.es
}

\section{Resumen}

This paper constitutes an attempt to establish the criteria used by the most important monolingual dictionaries of Spanish language, published in the nineteenth century, in order to introduce neologisms. For achieve this objective, I start from the collection of neologisms compiled by V. Salvá in his Nuevo Diccionario de la Lengua Castellana (1846), contrasting his labour whit that developed by the others lexicographers of this period and, very specially, with the different issues of the DRAE in the nineteenth century.

\section{Introducción}

Uno de los capítulos problemáticos de la historia de la lexicografía española es, sin duda, el que concierne a la incorporación de neologismos en los diccionarios generales de la lengua. La práctica tradicional -seguida hasta nuestros días por el $D R A E$ - se ha fundamentado en un concepto de norma culta en el que predomina sobre todo el peso de la tradición literaria, entendida como modelo de lengua, y menos el uso de los hablantes cultos. Es por ello que los diccionarios normativos, como es el caso del académico, a la hora de dar cuenta de la variación diacrónica, inclinan la balanza a favor del léxico anticuado, cuya presencia en los textos literarios garantiza su legitimidad, frente al léxico de reciente instalación en la lengua -ya se trate de préstamos, ya de voces de creación interna-, aunque su uso se haya generalizado entre los hablantes.

El propósito que anima nuestra investigación es poner de manifiesto los criterios que subyacen a la incorporación de neologismos en los principales diccionarios monolingües del español de los siglos XIX y XX. Para alcanzar este objetivo, partiremos de la colección de neologismos léxicos incorporados por V. Salvá en su Nuevo Diccionario de la Lengua Castellana (1846), contrastando su labor con la llevada a cabo por otros lexicógrafos de este mismo periodo y, especialmente, con la de la Academia, a través del seguimiento de las diferentes ediciones del $D R A E$ y de otros diccionarios elaborados por la docta Corporación.

1 Este trabajo ha sido posible gracias al Proyecto BFF2002-02442 del Ministerio de Ciencia y Tecnología y al Proyecto "Construcciones paratácticas en español. Modelos cognitivos y procesos de tipología sintagmática" del Programa Séneca 2000 de la Comunidad Autónoma de la Región de Murcia. 
Por razones de espacio, dejamos para otra ocasión el seguimiento de estas voces en los lexicógrafos de la tradición no académica.

\section{El Nuevo Diccionario de Salvá}

En trabajos anteriores (Azorín Fernández, 2000 y 2003) hemos destacado diversos aspectos de la labor llevada a cabo por Vicente Salvá en su faceta de corrector y adicionador del DRAE. Tarea en la que logró sobresalir allí donde otros autores de su época no harían sino plagiar a la Academia o, en el mejor de los casos, incrementar el Diccionario académico con añadidos de escaso interés ${ }^{2}$.

Siguiendo la tónica del momento, Salvá había publicado en 1838 y 1841 , con destino al mercado hispanoamericano, sendas ediciones de la octava entrega del DRAE $(1837)^{3}$. Pero es en el Nuevo Diccionario de la Lengua Castellana (1846) donde se encuentra la aportación más original de nuestro autor a la lexicografía española. En esta obra no sólo se corrigen las erratas de la novena edición del Diccionario de la Academia -que será la base utilizada - sino que se añade un considerable monto de informaciones para completarlo y suplir sus deficiencias. La decisión de publicar esta nueva edición del DRAE vendría dictada por la buena acogida dispensada en América a las dos anteriores y, sobre todo, por la creciente demanda de nuevos ejemplares. Es así como Salvá se decide a llevar a cabo una nueva entrega, esta vez aumentada con todas las anotaciones que había ido reuniendo a to largo de su vida. Hay que decir que, desde hacía años, nuestro autor acariciaba la idea de publicar, como apéndice del DRAE, un "Suplemento"4 donde se diera cabida a todas esas informaciones, aunque, a la postre, ese "Suplemento"s aparecería fundido con el texto de la Academia y no como parte exenta por expreso deseo de Salvá.

Los materiales originales presentes en el Nuevo Diccionario, según nuestros recuentos, suman un total de 31.182 adiciones que, a su vez, podríamos dividir en dos grandes bloques: el de las voces con algún tipo de marcación $-16.517-$ y el de las no marcadas o generales $-14.665-$.

2 La baja calidad de algunos de estos subproductos lexicográficos se debió, en parte, a las circunstancias en que fueron elaborados. Obras de urgencia, en su mayoría, destinadas a atender la demanda de las ex-colonias españolas de América, como ha explicado Manuel Seco (2003: 259-261). También Salvá se vio inmerso en la misma encrucijada que muchos de estos autores y, gracias a su talento y a su extremada profesionalidad, lograría culminar con éxito todas sus empresas diccionarísticas.

3 Aunque respeta integramente el texto académico, fueron numerosas las correcciones técnicas introducidas por Salvá en estas dos ediciones del $D R A E$. Así, intercala en el orden alfabético de la macroestructura las voces del Suplemento de 1837; corrige las erratas advertidas por la propia Academia; corrige desviaciones del orden alfabético; separa artículos incluidos por error dentro de otros, etc. Véase a este respecto el trabajo de Pedro Álvarez de Miranda (2003), donde se ofrece un pormenorizado estudio de las características de estas dos ediciones preparadas por Vicente Salvá.

4 En el Prólogo a la edición que preparó en 1838 de la octava entrega del $D R A E$, declara Salvá que: "Habiendo llegado a reunir materiales suficientes para amalgamarlos con aquella obra [se refiere a la $8^{\mathrm{a}}$ del $D R A E$ ] y formar una que pudiera pasar por nueva, no me he resuelto a hacerlo, prefiriendo reproducir el texto de la Academia, y dar por más adelante un Suplemento que reúna cuantos aumentos y observaciones haya podido acopiar" (Salvá, 1838a: VII).

5 Como es sabido, Salvá no se contentó con añadir al final de la novena edición del $D R A E$ sus anotaciones, sino que las intercaló en el lugar correspondiente de la macroestructura y de la microestructura, utilizando un sencillo sistema de marcas de acotación. Es decir, que el "Suplemento" entraría a formar parte del propio texto académico, facilitando de este modo las consultas de los lectores (Azorín Fernández, 2003: 121-22). 
Estas cifras hablan por si solas de la importante labor realizada por nuestro lexicógrafo; aunque, más que el aspecto cuantitativo del logro, habría que destacar el trabajo experto de Salvá como filólogo que, además, conoce por su experiencia como editor las principales carencias del Diccionario de la Academia Española.

Entre las voces marcadas, sobresale el conjunto integrado por aquéllas que presentan alguna acotación de tipo diacrónico, tal como se comprueba en la tabla siguiente:

TABLA 1

DISTRIBUCIÓN DE LAS VOCES MARCADAS

EN EL NUEVO DICCIONARIO (1846) DE SALVÁ

\begin{tabular}{|c|c|c|c|c|c|}
\hline DIACRÓNICA & DIATÓPICA & $\begin{array}{c}\text { DIASTRA/ } \\
\text { DIAFÁSICA }\end{array}$ & DIATÉCNICA & $\begin{array}{c}\text { DESPL. } \\
\text { SEMANT. }\end{array}$ & TOTAL \\
\hline 11.113 & 1.749 & 1.032 & 1.035 & 1.598 & 16.517 \\
\hline
\end{tabular}

Sorprende, además, que sea el de las antiguas el grupo de voces marcadas diacrónicamente mejor atendido en el Nuevo Diccionario, como se puede constatar acudiendo a las cifras que insertamos en la tabla 2. En términos porcentuales, las voces antiguas vienen a representar algo más del $32 \%$ del total de las adiciones; esto es, casi un tercio del conjunto del "Suplemento" tantos años trabajado por Vicente Salvá. Estas cifras vendrían a confirmar que, en opinión de nuestro lexicógrafo, una de las principales carencias del $D R A E$, radicaría en la insuficiente representación de este sector del léxico marcado, a pesar de reconocer que "las palabras anticuadas, [...] han sido siempre muy atendidas en el Diccionario" de la Academia (Salvá, 1846a: XXIII). Sin embargo, teniendo en cuenta el peso de nuestra literatura medieval y clásica, Salvá considera todavía restrictivo en exceso el criterio de selección de la RAE a la hora de dar cabida a las voces antiguas ${ }^{6}$; sobre todo, pensando en las necesidades de los usuarios, cuyas consultas al Diccionario académico, particularmente si se trata de lectores extranjeros, tienen como objetivo el significado de las palabras usadas por nuestros escritores clásicos.

TABLA 2

VOCES CON MARCACIÓN DIACRÓNICA EN EL NUEVO DICCIONARIO (1846) DE SALVÁ

\begin{tabular}{|l|c|c|c|c|}
\hline ANTIGUAS & POCO USADAS & ANT/POCO US. & NEOLOGISMOS & TOTAL \\
\hline 10.315 & 509 & 34 & 255 & 11.113 \\
\hline
\end{tabular}

6 La Academia admite "según tengo entendido - dice Salvá- a las que están apoyadas en tres autores diversos" (Salvá, 1846a: XXIV). Evidentemente, nuestro autor se muestra partidario de adoptar un criterio más amplio que dé entrada a un mayor número de voces antiguas. 


\title{
3. Los neologismos en el Nuevo Diccionario
}

El lugar privilegiado que en el plan de Salvá ocupan las voces antiguas no es obstáculo para que, en el Nuevo Diccionario, se detecte también la voluntad de su autor de registrar los usos comúnmente extendidos entre los hablantes. En este sentido, las voces del estilo familiar, los tecnicismos de reciente introducción en determinados ámbitos de especialidad (Azorín Fernández, 2002) y, sobre todo, los neologismos presentes en la obra, abundarían en esa dirección que denota en nuestro autor una mayor flexibilidad a la hora de registrar las variedades del español más alejadas del núcleo culto común, anclado fundamentalmente en la lengua literaria, frente a la actitud más conservadora que caracteriza a la Academia.

La postura de Salvá a cerca de la naturalización de las voces y expresiones de reciente creación es bastante moderada. Así, en su Gramática castellana, concretamente en el capítulo titulado "Del lenguaje castellano actual" , el autor condena como vicios en el uso del idioma tanto el casticismo exagerado de quienes, teniendo como único modelo a los clási$\cos$, no conceden margen alguno a las formaciones neológicas que la lengua requiere para adaptarse a las necesidades de los hablantes; como, en el extremo opuesto, la ligereza de los que incurren en la adopción inmoderada de neologismos superfluos al dictado de modas pasajeras. Así, pues, para Salvá (1988: 711-712):

\begin{abstract}
Dos vicios deben huirse igualmente en toda lengua viva: incurren en uno los que están tan aferrados a los escritores clásicos que nos han precedido, que no creen pura y castiza una voz si no está autorizada por ellos; y el otro, que es el más frecuente, como que se hermana mucho con la ignorancia, consiste en adoptar sin discreción nuevos giros y nuevas voces, dando a las cosas que ya conocieron y llamaron por su nombre nuestros antepasados, aquel con a que nuestros vecinos les place designarlas ahora. Para hablar con pureza el castellano conviene evitar uno y otro escollo; y pues nuestra lengua debe a la latina gran parte de su riqueza, de ella pueden tomarse las palabras de que tuviéramos una absoluta necesidad, acomodándolas a la inflexión y genio del español [...] Con menos recelo pueden adoptarse las palabras que para las ciencias y artes se requieran, o hayan empleado ya los escritores de otras naciones, sacadas de la lengua griega, que es el depósito universal de las nomenclaturas técnicas.
\end{abstract}

No se puede decir, por tanto, que la posición de Salvá difiera mucho de la sustentada por la Academia, salvo en la mayor apertura que nuestro autor manifiesta a la hora de adoptar las formaciones neológicas propias de las lenguas de especialidad ${ }^{8}$. Pero en lo que concierne a las voces de la lengua general, se muestra partidario de no ceder ante el neologismo innecesario, sobre todo, cuando se trata de un préstamo tomado de la lengua francesa:

7 Todas las referencias a la Gramática castellana de Salvá pertenecen a la edición crítica de Margarita Lliteras (1988). El capítulo al que nos referimos, en las tres primeras ediciones de la Gramática, lleva por título "Del estilo castellano actual" (Lliteras, 1988: 712).

8 Pues, mientras para la RAE, "tales voces pertenecen a todos los idiomas y a ninguno de ellos" (RAE, 1843": V), y sólo habrian de admitirse en el Diccionario aquellas que "se repiten en la conversación, se encuentran en los libros y llegan a ser de uso tan vulgar, que todas las personas de alguna cultura los comprenden y emplean, aun cuando no hayan saludado la ciencia à que debieron su origen" (RAE, $1843^{\mathrm{a}}$ : VI), la Academia se mostró mucho menos receptiva que Salvá a la hora de incorporar al diccionario los neologismos técnicos ampliamente difundidos $y$ asentados en el uso de las personas instruidas no especialistas. 
Hemos de ser sumamente cautos en todo lo que recibimos de los franceses, -dirá- ya porque la índole de la suya es, sin parecerlo, muy diversa de la de nuestra lengua; ya porque el roce con los de esta nación y la continua lectura de sus libros no pueden menos de llenarnos la cabeza con sus idiotismos, haciéndonos olvidar los nuestros (Salvá: $1988,712)$.

Con todo, Salvá no deja de reconocer que el uso es determinante cuando se trata de legitimar una voz o un giro por muy alejados que estos se encuentren de las estructuras léxico-semánticas de nuestra lengua. Es - dirá- la "ley irresistible del uso", ante la que necesariamente han de claudicar las normas que se intentan imponer desde las instancias competentes. Aunque para nuestro lexicógrafo el uso al que se debe atender no es otro que "la autoridad de los escritores más distinguidos" (Salvá, 1988: 712).

No son muchos los vocablos que Salvá introduce con la marca de neologismo, pues, para ser exactos, a los 255 que hemos localizado con este tipo de sanción, habría que restar los 36 que ya figuraban en el $D R A E$, aunque sin la especificación expresa que los identificara como neologismos. La mayoría de estas voces están ya presentes en la novena edición del diccionario académico (1843); y una pequeña parte - tan sólo 8 elementos- figuraban en entregas anteriores. Son, por tanto, 219 los neologismos recopilados e introducidos por Salvá como contribución personal.

Según declara en la "Introducción" del Nuevo Diccionario, el criterio que utiliza nuestro autor para calificar un determinado vocablo o acepción como neologismo es, además de su cronología de recepción en la lengua, la comprobación de que su uso se halle generalizado entre el común de los hablantes $o$, al menos, que forme parte del repertorio de los escritores reputados de correctos:

Cuando [...] llamo neológica a una voz, doy a entender que ha sido introducida en lo que va de este siglo; pero que descansa en el uso general o en la autoridad de escritores correctos, de modo que no debe temerse faltar, empleándola, a las reglas del buen lenguaje (Salvá, 1846a: XXVII).

Es decir que no solo basta la comprobación de que la voz candidata a neologismo sea, efectivamente, de reciente introducción, sino que al usuario hay que proporcionarle la certeza de no estar incurriendo en falta cuando la utilice. Finalmente, Salvá divide las palabras nuevas en dos categorías bien diferenciadas:

Las que introducidas recientemente para designar objetos que antes no se conocían, son de uso universal o tienen la aprobación de los que escriben con cuidado [y las que] tomadas sin necesidad de nuestros vecinos, se hayan generalizadas en todas las clases de la nación, en razón de las guerras que con ellos hemos tenido, de las relaciones de comercio que nos unen, de la continua lectura de los autores, y aun de las traducciones que continuamente salen a la luz. (Salvá, 1846a: XXVII).

Las primeras no presentan ningún problema a la hora de recibirlas en el diccionario, siempre que la adaptación a nuestra lengua se haya llevado a efecto; en cambio, las segundas sólo serán admitidas cuando se trate de un uso imposible de desarraigar. Por esta razón, firma Salvá: 
He aquí explicado porque doy entrada a cupé, papillota, pupitre, quinqué, rango y tilburi, palabras tanto o más comunes que ambigú, cabriolé, carretela, fricandó, glasé, tremó, etc., y no me decido a admitir a brochura, hacer el amor, moción ni a susceptibilidad, que van siendo de moda. Si he dado cabida a las dos últimas voces, a la frase erigirse en, a consagrar por dedicar, a congregarse por sacrificarse, a revancha y a algunas otras de igual ralea, ha sido expresando que no las tengo por suficientemente autorizadas; pero he preferido ponerlas, mas bien que a dar lugar a que sean olvidadas (Salvá, 1846a: XXVII).

La serie que Salvá cita como ejemplo de neologismos por préstamo que designan objetos o ideas nuevos y son voces de uso común, figuraba ya en distintas ediciones del Diccionario académico: ambigú (Autoridades, 1770), cabriolé (DRAE, 1803), carretela (DRAE, 1837), fricandó $(D R A E, 1791)$, glasé (DRAE, 1780) y tremó (DRAE, 1817). Por la misma razón, nuestro lexicógrafo introduce las también frecuentes en la lengua general: cupé, papillota, pupitre, quinqué, rango y tílburi que, más tarde, entrarían a formar parte del repertorio oficial -papillota como papillote-. No sucede lo mismo con aquellas que no cumplen con el requisito de designar conceptos que se refieran a objetos o formas nuevas de concebir las relaciones del individuo con su entorno; en este caso, Salvá opta por no introducir la voz en el Diccionario, como sucede con brochura o hacer el amor, o bien por acompañar la definición de este tipo de palabras con la correspondiente nota de carácter normativo, informando al usuario de su dudosa legitimidad. Por ejemplo:

S. V. EXPLOTAR Met. Sacar todo el partido posible, aunque sea traspasando los términos regulares y justos, de una persona o cosa; como N. Explota perfectamente a su tío o su empleo. Los buenos escritores se abstienen de usar voces de naturalización tan reciente como ésta.

Los 255 neologismos que Salvá introdujo en su Nuevo Diccionario de la Lengua Castellana, aunque representan una pequeña parte dentro del apartado de voces con marcación diacrónica, forman un conjunto de gran interés para el estudio de la reciente historia de nuestro léxico y más aún de cara a dilucidar los criterios utilizados por uno de nuestros más conspicuos diccionaristas. La mayoría de las formaciones neológicas que Salvá recoge han permanecido en nuestra lengua, siendo muchas de ellas voces de uso frecuente en la lengua actual. Pero, sin duda, son muestra también de la atención prestada por el autor a la lengua viva y a los cambios que ésta experimenta para seguir adaptándose a las necesidades de los hablantes. Muestra, al fin, cabría pensar, de la responsabilidad del lexicógrafo que debe actuar como notario y guía, a la vez, del uso de sus contemporáneos.

\section{Advertencia sobre la edición del glosario}

En el glosario que a continuación presentamos, hemos recogido la totalidad de los neologismos que Salvá incorporó a su Nuevo Diccionario de la Lengua Castellana. En él damos cuenta de toda la información que aparece en el repertorio original, bien se trate de un artículo independiente, bien se trate de una acepción añadida a algún artículo ya existente.

Hemos respetado la ortografía de Salvá excepto en la acentuación que regularizamos según las normas actualmente en vigor.

Acompañamos la definición con la marca [Neol] sólo en los casos en que Salvá se limita a señalar el carácter neológico de una acepción ya contenida en el $D R A E$ (1843). 
Nuestro glosario termina siempre indicando la fecha de recepción por parte de la Academia del neologismo de que se trate. En el caso de acepciones no recogidas por la RAE en ninguno de sus repertorios, señalamos este hecho con el símbolo $\varnothing$.

Para el seguimiento cronológico de la recepción por parte de la RAE de los neologismos de Salvá, nos hemos valido del Nuevo Tesoro Lexicográfico publicado por la Academia en 2001, en formato DVD. No obstante, en la bibliografia que acompaña a este trabajo, proporcionamos la referencia completa de todos los diccionarios citados en el glosario para una más rápida identificación de los mismos.

\section{Referencias bibliográficas}

Álvarez de Miranda, Pedro (2002): "En torno al Nuevo diccionario de la lengua castellana de Vicente Salvá". En M. T. Echenique y J. Sánchez (eds.): Actas del V Congreso Internacional de Historia de la Lengua española (Valencia 31 de enero al 4 de febrero de 2000), Madrid, Gredos, págs. 1875-1887.

Azorín Fernández, Dolores (2000): Los diccionarios del español en su perspectiva histórica. Alicante, Publicaciones de la Universidad de Alicante.

Azorín Fernández, Dolores (2002): "Salvá y la Academia Española: dos posturas frente a la recepción de los tecnicismos en el diccionario de la lengua". En Esparza Torres, M. A., B. Fernández Salgado y H. J. Niederehe (eds.): Estudios de Historiografia Lingüistica. Actas del III Congreso Internacional de la Sociedad Española de Historiografia Lingüistica. (Vigo, 7-10 de febrero de 2001) Hamburgo, Helmut Buske Verlag, págs. 777-788.

Azorín Fernández, Dolores (2003): "Un proyecto original en la lexicografia española del siglo XIX: el Nuevo Diccionario de la Lengua Castellana (1846) de Vicente Salvá". En Lexicografia y lexicología en Europa y en América. Homenaje a Günther Haensch. Valencia, Gredos-Biblioteca Valenciana, págs. 115-131.

Lliteras, Margarita (1988): "Estudio introductorio" a su edición de Vicente Salvá, Gramática de la Lengua Castellana- 2 vols., Madrid, Arco/Libros, págs. 7-64.

Real Academia Española [1726-1739] 1963: Diccionario de Autoridades. Madrid, Gredos.

Real Academia Española (1770): Diccionario de la Lengua Castellana por la Real Academia Española. Segunda impresión corregida y aumentada. Tomo primero. A-B. Madrid, Imprenta de Joachín Ibarra.

Real Academia Española (1780): Diccionario de la Lengua Castellana compuesto por la Real Academia Española, reducido a un tomo para su más fácil uso. Madrid, Joachín Ibarra.

Real Academia Española (1803): Diccionario de la Lengua Castellana por la Real Academia Española. Cuarta edición. Suplemento. Madrid, Viuda de Ibarra.

Real Academia Española (1832): Diccionario de la Lengua Castellana por la Real Academia Española. Séptima edición. Suplemento. Madrid, Imprenta Real.

Real Academia Española (1837): Diccionario de la Lengua Castellana por la Real Academia Española. Octava edición. Madrid, Imprenta Nacional.

Real Academia Española (1843a): "Prólogo" en Diccionario de la Lengua Castellana por la Real Academia Española. Novena edición. Madrid, Imprenta de Francisco María Fernández, págs. V-VI.

Real Academia Española (1843b): Diccionario de la Lengua Castellana por la Real Academia Española. Novena edición Madrid, Imprenta de Francisco María Fernández.

Real Academia Española (1852): Diccionario de la Lengua Castellana por la Real Academia Española. Décima edición. Madrid, Imprenta Nacional. 
Real Academia Española (1869): Diccionario de la Lengua Castellana por la Real Academia Española Undécima edición. Madrid, Imprenta de Don Manuel Rivadeneyra.

Real Academia Española (1884): Diccionario de la Lengua Castellana por la Real Academia Española. Duodécima edición. Madrid, Imprenta de D. Gregorio Hernando.

Real Academia Española (1899): Diccionario de la Lengua Castellana por la Real Academia Española. Décimatercia edición. Madrid, Imprenta de los Señores Hernando y compañía.

Real Academia Española (1914): Diccionario de la Lengua Castellana por la Real Academia Española. Decimocuarta edición. Madrid, Imprenta de los sucesores de Hernando.

Real Academia Española (1925): Diccionario de la Lengua Española por la Real Academia Española. Décima quinta edición. Madrid, Espasa-Calpe.

Real Academia Española (1927): Diccionario Manual e Ilustrado de la Lengua Española. Madrid, Espasa-Calpe.

Real Academia Española (1936): Diccionario de la Lengua Española por la Real Academia Española. Décima sexta edición. Madrid, Espasa-Calpe.

Real Academia Española (1933): Diccionario Histórico de la Lengua Española. Tomo I-A. Madrid, Imprenta de Librería y Casa Editorial Hernando.

Real Academia Española (1956): Diccionario de la Lengua Española por la Real Academia Española. Décimoctava edición. Madrid, Espasa-Calpe.

Real Academia Española (1970): Diccionario de la Lengua Española por la Real Academia Española. Décimo novena edición, Madrid, Espasa-Calpe.

Real Academia Española (1983): Diccionario de la Lengua Española por la Real Academia Española. Vigésima edición. Madrid, Espasa-Calpe.

Real Academia Española (1992): Diccionario de la Lengua Española por la Real Academia Española. Vigésima primera edición. Madrid, Espasa-Calpe.

Real Academia Española, Nuevo Tesoro Lexicográfico de la Lengua Española, Madrid, Espasa-Calpe, 2001 (2 DVD).

Salvá, Vicente (1988): Gramática de la Lengua Castellana 2 vols. (Edición de Margarita Lliteras) Madrid, Arco/Libros.

Salvá, Vicente (1838a): "Advertencia del editor", Diccionario de la Lengua Castellana por la Academia Española, reimpreso de la octava edición publicada en Madrid en 1837. París, Librería de Don Vicente Salvá, págs. VII-XXVII.

Salvá, Vicente (1838b): Diccionario de la Lengua Castellana por la Academia Española, reimpreso de la octava edición publicada en Madrid en 1837. París, Librería de Don Vicente Salvá.

Salvá, Vicente (1846a): "Introducción del adicionador", Nuevo Diccionario de la Lengua Castellana. París, Librería de Don Vicente Salvá, págs. VII-XXXVII.

Salvá, Vicente (1846b): Nuevo diccionario de la Lengua Castellana. París, Librería de Don Vicente Salvá.

Seco, Manuel (2003): "El nacimiento de la lexicografía española no académica". En Estudios de lexicografía española. Madrid, Gredos, págs. 259-284. 
Glosario de neologismos introducidos por Vicente Salvá en el Nuevo Diccionario de la Lengua Castellana (1846)

\section{aberración}

Met. [Neol] Descarrío [extravío, desconcierto].

Recepción RAE: DRAE, 1914.

\section{abonar}

Suscribirse a un papel, libro u otra cosa, pagando anticipado su valor, u obligándose a satisfacerlo bajo ciertas condiciones.

Recepción RAE: DRAE, 1817.

\section{absolutismo}

[Neol] Sistema de gobierno absoluto.

Recepción RAE: DRAE, 1843.

\section{absolutista}

[Neol] Partidario del gobierno absoluto.

Recepción RAE: DRAE, 1843.

\section{acelerador}

El que acelera.

Recepción RAE: DRAE, 1925.

\section{aceleratriz}

La que acelera

Recepción RAE: DRAE, 1925.

\section{acra o acre}

Medida de tierra usada por los extranjeros, que no es la misma en todas las naciones, pero consta regularmente de 160 pérticas.

Recepción RAE: DRAE, 1899.

\section{adepto, ta}

[Neol] El que estaba iniciado en los arcanos de la alquimia y por extensión se dice de los filiados en alguna secta o asociación particular, y especialmente si es clandestina. Recepción RAE: DRAE, 1843.

\section{adherencia}

Unión de una cosa a otra.

Recepción RAE: DRAE, 1852.

\section{adherencia}

Adhesión, parcialidad.

Recepción RAE: $\varnothing$. 


\section{adherir}

Estar pegado a otra cosa.

Recepción RAE: DRAE, 1869.

\section{adhesivo, va}

Lo que está pegado a otra cosa.

Recepción RAE: DRAE, 1884.

\section{afrancesado, da}

El español que siguió el partido de Napoleón durante la guerra que éste hizo a la península.

Recepción RAE: DRAE, 1852.

\section{afrancesar}

Dar un giro francés a la dicción, afearla con galicismos.

Recepción RAE: DRAE, 1925.

\section{afrancesar}

Imitar las modas o costumbres de los franceses.

Recepción RAE: DRAE, 1925.

\section{afrancesar}

Cometer galicismos.

Recepción RAE: $\varnothing$.

\section{agencia}

La oficina o despacho de uno o varios agentes.

Recepción RAE: DRAE, 1852.

\section{agenciar}

Manejarse, gobernarse.

Recepción RAE: $\varnothing$.

\section{agolpamiento}

Acción y efecto de agolparse.

Recepción RAE: DRAE, 1884.

\section{agoticado, da}

Lo hecho a imitación del gusto gótico.

Recepción RAE: $\varnothing$.

\section{agradablemente}

Con gusto, en diversiones, alegremente.

Recepción RAE: DRAE, 1884. 


\section{agradablemente}

Cortésmente, con agrado.

Recepción RAE: $\varnothing$.

\section{álbum}

Voz latina que designa un librito de memoria que llevan algunos viajeros para recoger las firmas de personas distinguidas, o alguna máxima escrita de mano de las mismas. Recepción RAE: DRAE, 1869.

\section{álbum}

Cuaderno de dibujo, piezas de música, o de trozos escogidos en prosa o verso. Recepción RAE: DRAE, 1869.

\section{alegorista}

El que explica el sentido de las cosas por alegorías.

Recepción RAE: $\varnothing$.

\section{amnistiar}

[Neol] Conceder amnistía.

Recepción RAE: DRAE, 1843.

\section{anarquía}

Confusión de los poderes de un estado.

Recepción RAE: DRAE, 1852.

\section{anarquía}

Met. Alboroto, trastorno del orden público.

Recepción RAE: DRAE, 1869.

\section{anarquista}

[Neol] El que desea o promueve la anarquía.

Recepción RAE: DRAE, 1843.

\section{animosidad}

[Neol] Ojeriza tenaz.

Recepción RAE: DRAE, 1843.

\section{antagonismo}

Rivalidad, oposición.

Recepción RAE: DRAE, 1869.

\section{anticonstitucional}

Contrario a la constitución o ley fundamental del estado.

Recepción RAE: DRAE, 1925. 


\section{antiministerial}

Contrario a los principios políticos que siguen los ministros del estado.

Recepción RAE: DRAE, 1936.

\section{antimonárquico, ca}

Lo que se opone a los principios que constituyen la monarquía.

Recepción RAE: DRAE, 1869.

\section{antinacional}

Lo que es opuesto a la prosperidad y los progresos de la nación.

Recepción RAE: $\varnothing$.

\section{antirevolucionario, ria}

Enemigo de todo movimiento popular cualquiera que sean su origen o tendencia.

Recepción RAE: DHLE, 1933.

\section{antisocial}

Lo que es contrario a la sociedad humana.

Recepción RAE: DRAE, 1869.

\section{aplomo}

Tacto, tino, cordura.

Recepción RAE: DRAE, 1899.

\section{arborización}

Ramaje que se halla naturalmente dibujado en algunas piedras.

Recepción RAE: DMILE, 1927.

\section{arborizado, da}

Lo que presenta las ramificaciones de un árbol o un arbusto: se dice de las piedras que tienen tales dibujos en sus cortes.

Recepción RAE: DRAE, 1933.

\section{argentino, na}

Lo que pertenece al Río de la Plata, como república Argentina.

Recepción RAE: DRAE, 1869.

\section{articulista}

[Neol] El que escribe artículos o discursos para que se inserten en algún papel público. Recepción RAE: DRAE, 1843.

\section{ateneo}

Edificio donde se reúnen voluntariamente algunos literatos y aficionados a las bellas artes, para difundir agradablemente su conocimiento y el de varios ramos del saber humano. Recepción RAE: DRAE, 1884. 


\title{
atisbo
}

Asomo, destello, indicio ligero.

Recepción RAE: DRAE, 1884.

\section{atrapar}

Coger accidentalmente, como ATRAPAR un resfriado.

Recepción RAE: DRAE, 1869.

\section{aurista}

El que hace profesión de curar las enfermedades de los oídos.

Recepción RAE: DMILE, 1927.

\section{banca}

El comercio de girar o descontar una letra.

Recepción RAE: DRAE, 1869.

\section{hacer la banca, s.v. banca}

Dedicarse una casa al giro o descuento de letras como objeto principal de su comercio. Recepción RAE: $\varnothing$.

\author{
batir \\ Vencer, derrotar al enemigo. \\ Recepción RAE: DRAE, 1899.
}

\section{batir}

Pelear, reñir dos o más personas, y así se dice BATIRSE en duelo, BATIRSE dos ejércitos. Recepción RAE: DRAE, 1869.

\section{bazar}

Reunión de muchas tiendas bajo de un mismo edificio o de una calle cubierta de cristales. En oriente llaman bazares a todos los sitios destinados al tráfico y comercio, y de ahí se ha proahijado esta denominación.

Recepción RAE: DRAE, 1869.

\section{bidé}

Mueble de cámara que tiene una palancana prolongada, para sentarse sobre ella y lavarse con comodidad.

Recepción RAE: DRAE, 1899.

billete de banco, $s$. v. billete

Papel moneda puesto en circulación por los bancos legalmente autorizados. Recepción RAE: DRAE, 1884. 


\section{candidato}

El que va propuesto en las listas que se circulan cuando está inmediata la elección de senadores o diputados a cortes, aunque él no pretenda ni quiera serlo.

Recepción RAE: DRAE, 1884.

\section{candidatura}

La lista de candidatos para el cargo de senadores o diputados a cortes.

Recepción RAE: DRAE, 1914.

\section{carta}

La constitución actual de Francia.

Recepción RAE: $\varnothing$.

\section{carta de seguridad, $s . v$. carta}

Papeleta que se da a los vecinos de un pueblo o los que demoran en él por algún tiempo, para no ser molestados como desconocidos o sospechosos.

Recepción RAE: $\varnothing$.

\section{Céntima o céntimo}

La centésima parte de un franco, moneda francesa.

Recepción RAE: $\varnothing$.

\section{cesante}

El empleado público que deja de serlo por resultas de alguna reforma política o económica.

Recepción RAE: DRAE, 1852.

\section{cesantía}

La calidad de cesante en un empleado público.

Recepción RAE: DRAE, 1852.

\section{cinismo}

Impudicia, obscenidad.

Recepción RAE: DRAE, 1869.

\section{civismo}

El celo de un ciudadano por la independencia y libertad de su patria.

Recepción RAE: DRAE, 1869.

\section{clisaje}

La acción y efecto de clisar.

Recepción RAE: $\varnothing$. 


\section{clisar}

[Neol] Dejar caer prona y perpendicularmente una matriz sobre el metal derretido para que en él quede estampada la imagen grabada de aquélla [Tal es el método que se emplea para politipar. Ahora se reproducen muy de diverso modo, en relieve y en planchas de metal o de un betún muy duro, las páginas compuestas con caracteres movibles o los grabados de un realce proporcionado, que es el objeto del clisaje].

Recepción RAE: DRAE, 1832.

\section{club}

[Neol] Junta de individuos de alguna sociedad política, por lo común clandestina.

Recepción RAE: DRAE, 1837.

\section{compacción}

La trabazón fuerte y cerrada de los cuerpos compactos.

Recepción RAE: $\varnothing$.

\section{conscripción}

El reclutamiento o quinta que hacen los franceses para reemplazar el ejército.

Recepción RAE: DMILE, 1927.

\section{conscripto o conscrito}

El recluta o quinto del ejército francés.

Recepción RAE: DMILE, 1927.

\section{contabilidad}

El modo de formar y dar cuentas.

Recepción RAE: DRAE, 1852.

\section{contrarevolución}

Revolución política que tiene el objeto de destruir los resultados de la que inmediatamente la ha precedido.

Recepción RAE: DRAE, 1884.

\section{contrarevolucionar}

Conmover una ciudad, provincia, etc. En sentido contrario a la revolución política acaecida en ella.

Recepción RAE: $\varnothing$.

\section{contrarevolucionar}

Promover una contrarevolución.

Recepción RAE: $\varnothing$.

\section{contrarevolucionario, ria}

El que promueve alguna contrarevolución o es adicto a ella.

Recepción RAE: DRAE, 1983. 


\section{copiador}

Máquina que sirve para copiar cualquier escrito. Su uso más frecuente es el de copiar cartas. Las hay de muy diversas estructuras.

Recepción RAE: $\varnothing$.

\section{coqueta}

[Neol] La mujer que por vanidad procura agradar a muchos. Es voz tomada del francés. Recepción RAE: DRAE, 1843.

\section{coquetear}

[Neol] Tener ademanes o conducta de coqueta.

Recepción RAE: DRAE, 1843.

\section{coquetería}

[Neol] Vicio de coquetear.

Recepción RAE: DRAE, 1843.

\section{coquetería}

[Neol] Cierta afectación estudiada en los modales y adornos para mayor atractivo.

Recepción RAE: DRAE, 1843.

\section{coquetismo}

Coquetería.

Recepción RAE: DRAE, 1925.

\section{costurero}

Mesita de labor de las señoras.

Recepción RAE: DRAE, 1852.

\section{departamental}

Lo que pertenece a algún departamento.

Recepción RAE: DMILE,1927.

\section{desfachatado, da}

Descarado, desvergonzado.

Recepción RAE: DRAE, 1869.

\section{desfachatez}

Descaro, desvergüenza.

Recepción RAE: DRAE, 1852.

\section{desnacionalizar}

Hacer perder el carácter nacional. Es más usado como recíproco.

Recepción RAE: DRAE, 1956. 


\section{desorganización}

[Neol] La acción y el efecto de desorganizar [y desorganizarse].

Recepción RAE: DRAE, 1843.

\section{desorganizador, ra}

[Neol] El que desorganiza.

Recepción RAE: DRAE, 1843.

\section{desorganizar}

[Neol] Desarreglar, desordenar en sumo grado.

Recepción RAE: DRAE, 1837.

\section{desorientar}

Desalentar, aturdir, hacer perder el tino o dirección. Es muy usado como recíproco. Recepción RAE: DRAE, 1869.

\section{detallar}

[Neol] Tratar, referir alguna cosa por menor, por partes, circunstanciadamente.

Recepción RAE: DRAE, 1803.

\section{detallar}

Vender al menudeo.

Recepción RAE: DRAE, 1970.

\section{detalle}

[Neol] El pormenor o relación, cuenta o lista circunstanciada de alguna cosa.

Recepción RAE: DRAE, 1843.

\section{en detalle, s. v. detalle}

Por menor, por menudo.

Recepción RAE: $\varnothing$.

\section{devengar}

Adeudar o pagar, como el palo campeche DEVENGA 15 reales por quintal para su introducción; este papel DEVENGA intereses.

Recepción RAE: $\varnothing$.

\section{devengar}

Vencer, llegar el plazo de un pago; v. g.: las viudedades DEVENGAN el 20 de este mes. Recepción RAE: $\varnothing$.

\section{efectos públicos, $s . v_{\text {. efecto }}$}

Las rentas creadas por el gobierno y los billetes o papeles del estado que en distintas épocas se han introducido en el comercio.

Recepción RAE: $\varnothing$. 


\section{eliminar}

[Neol] Descartar, separar una cosa, prescindir de ella.

Recepción RAE: DRAE, 1843.

\section{emancipar}

Tomarse demasiada libertad para decir o hacer alguna cosa.

Recepción RAE: $\varnothing$.

\section{embalsamar}

Llenar de fragancia el aire, un cuarto, etc.

Recepción RAE: DRAE, 1884.

\section{emisión}

[Neol] El acto o efecto de emitir algún papel negociable.

Recepción RAE: DRAE, 1843.

\section{emitir}

Poner en circulación algún papel de los que se negocian en bolsa.

Recepción RAE: DRAE, 1852.

\section{emitir}

Exponer, manifestar; y en este sentido se dice EMIxIR la opinión sobre algún asunto. Recepción RAE: DRAE, 1884.

\section{emoción}

[Neol] Agitación repentina del ánimo.

Recepción RAE: DRAE, 1843.

\section{empeñante}

MutuataRio.

Recepción RAE: $\varnothing$.

\section{empresario, ria}

[Neol] El que tiene parte en [El que toma por su cuenta] alguna empresa, contribuyendo a ella con su capital, sufriendo las pérdidas o reportando las ganancias [como el EMPRESARIO de un teatro].

Recepción RAE: DRAE, 1843.

erigirse en amo, maestro, etc, $s . v$. erigir

Constituirse amo o maestro, hacer de amo o maestro.

Recepción RAE: DRAE, 1936.

\section{espionaje}

El oficio de espía.

Recepción RAE: DRAE, 1884. 


\section{estacionario, ria}

Parado, lo que no sigue su curso regular.

Recepción RAE: DRAE, 1884.

\section{estacionario, ria}

El que no adelanta o no progresa.

Recepción RAE: DRAE, 1884.

\section{estacionarse}

Pararse, no tener curso.

Recepción RAE: DRAE, 1884.

\section{estacionarse}

No adelantar, no progresar en algún ramo o en la carrera principiada.

Recepción RAE: DRAE, 1884.

\section{estagnación}

Met. Parada, falla de circulación o de movimiento: dícese de los humores, negocios mercantiles.

Recepción RAE: $\varnothing$.

\section{evaporar}

Met. Aliviar, desahogar la cólera, pena, etc.

Recepción RAE: DRAE, 1899.

\section{evaporarse}

Met. Perder por los años o cualquier accidente una gran parte del saber o buen juicio que alguno tenía.

Recepción RAE: DRAE, 1780.

\section{evitar á uno, $s$. v. evitar}

[Neol] Huir de tratarle, apartarle de su trato y comunicación.

Recepción RAE: DRAE, 1732.

\section{exagerado, da}

El que tiene ideas o proyectos fuera de los límites regulares.

Recepción RAE: $\varnothing$.

\section{exaltación}

El modo de pensar del que es exaltado.

Recepción RAE: $\varnothing$.

\section{exaltado, da}

El que en sus ideas políticas propende mucho hacia la libertad. Dícese también de las mismas ideas; y aplicado a personas suele usarse como sustantivo masculino y femenino. Recepción RAE: $\varnothing$. 


\section{exclusivismo}

El sistema de excluir absolutamente todo lo que no se acomoda a nuestros principios y modo de pensar, ora se trate de libros, ora de personas. Se aplica especialmente a los que nada hallan bueno en el que no sigue sus máximas políticas.

Recepción RAE: DRAE, 1869.

\section{explotación}

Beneficio, laboreo de una mina.

Recepción RAE: $\varnothing$.

\section{explotar}

Beneficiar, laborear las minas.

Recepción RAE: DRAE, 1869.

\section{explotar}

Met. Sacar todo el partido posible, aunque sea traspasando los términos regulares y justos, de una persona o cosa; como N. Explora perfectamente a su tío o su empleo. Los buenos escritores se abstienen de usar voces de naturalización tan reciente como ésta.

Recepción RAE: DRAE, 1925.

\section{exponer}

Hacer presente por medio de un memorial o representación.

Recepción RAE: $\varnothing$.

\section{exposición}

Memorial, representación.

Recepción RAE: DRAE, 1869.

\section{externo, na}

El niño o niña que está en un colegio, escuela o casa de educación, sin quedarse a dormir en ella; esto es, el que está de MEDIo pupILO.

Recepción RAE: DRAE, 1899.

\section{favoritismo}

La influencia que un favorito tiene en las acciones de la persona que le dispensa su predilección. Recepción RAE: DRAE, 1852.

\section{ferrocarril}

Camino en que los carruajes van por un carril de hierro, movidos ordinariamente por el vapor. Algunos le dan el nombre de camino de hierro, traduciendo servilmente de los franceses.

Recepción RAE: DRAE, 1852. 


\section{fijacarteles}

El que tiene por oficio fijar carteles y anuncios, en las esquinas y demás parajes acostumbrados de cada población.

Recepción RAE: $\varnothing$.

\section{Filiación}

Met. Procedencia directa; y así decimos la fiLIACión de las palabras, de las ideas, etc.

Recepción RAE: $\varnothing$.

\section{filiarse}

Alistarse en algún instituto, sociedad, etc.

Recepción RAE: DRAE, 1884.

\section{filón}

Veta o vena de una mina.

Recepción RAE: DRAE, 1869.

\section{folletín}

Los artículos de algunos periódicos, impresos de letra más menuda en la parte inferior de las páginas, que versan sobre puntos de literatura, o contienen cuentos, novelas o extractos de las obras recién publicadas, con el fin de hacer ver su objeto e importancia. Recepción RAE: DRAE, 1852.

\section{folletinista}

El que escribe folletines para algún periódico.

Recepción RAE: DRAE, 1852.

\section{fondos públicos, $s$. v. fondo}

El papel reconocido por el estado como deuda pasiva suya, lleve o no interés.

Recepción RAE: $\varnothing$.

\section{fusión}

Met. Se usa mucho ahora para significar la unión o reconciliación de los partidos políticos.

Recepción RAE: DRAE, 1852.

\section{gabán}

Especie de levita que no está ajustada al cuerpo.

Recepción RAE: DRAE, 1869.

\section{gabinete}

Ministerio, por el cuerpo de ministros de estado; y así se dice: consejo de GABINETE, el GABINETE no ha manifestado su opinión.

Recepción RAE: DRAE, 1899. 


\section{gastronomía}

El arte de preparar los regalos de la mesa.

Recepción RAE: DRAE, 1852.

\section{gastrónomo, ma}

El que tiene buena mesa o gusta de comer regaladamente.

Recepción RAE: DRAE, 1852.

\section{gavota}

Especie de tocata y de baile.

Recepción RAE: DRAE, 1852.

\section{gendarma ó gendarme}

El soldado de la gendarmería de Francia.

Recepción RAE: DRAE, 1869.

\section{gendarmería}

Nombre muy antiguo en Francia de ciertos cuerpos de caballería, pero que hoy designa la tropa de caballería destinada exclusivamente a conservar la tranquilidad pública y perseguir a los malhechores.

Recepción RAE: DRAE, 1869.

\section{guardasellos}

CANCILLER, por el secretario del rey.

Recepción RAE: DRAE, 1992.

\section{hablista}

El que habla o escribe con propiedad alguna lengua. Aunque solo se usa respecto de los que la hablan con corrección, suele añadirse algún adjetivo que así lo denota, diciendo: bueno, aventajado, etc. HABLISTA.

Recepción RAE: DRAE, 1869.

\section{hierro $=$ camino de hierro}

FERROCARRIL.

Recepción RAE: $\varnothing$.

\section{impermeabilidad}

La calidad de lo que es impermeable.

Recepción RAE: DRAE, 1899.

\section{impermeable}

[Neol] Impenetrable por el agua. Recepción RAE: DRAE, 1843. 


\section{imponer}

Colocar o entregar una cantidad para que produzca renta; y así decimos: pienso IMPONER tal suma en este banco o en aquellos fondos.

Recepción RAE: DRAE, 1852.

\section{importable}

Se dice de los géneros que pueden introducirse o importarse.

Recepción RAE: DRAE, 1992.

\section{inaugurar}

INSTALAR.

Recepción RAE: $\varnothing$.

\section{inconstitucional}

Lo que se opone a la constitución del estado.

Recepción RAE: DRAE, 1884.

\section{inscribir}

AlistaRse por escribirse en alguna lista.

Recepción RAE: DRAE, 1852.

\section{inseguir}

Seguir, proseguir, continuar; y así se dice: INSIGUIENDo en tal sistema.

Recepción RAE: $\varnothing$.

\section{insurreccional}

Lo que es propio de la insurrección o pertenece a ella.

Recepción RAE: DMILE, 1927.

\section{interior}

El cuerpo medio de los tres en que están divididos los coches de las diligencias.

Recepción RAE: DRAE, 1852.

\section{internacional}

Lo que pertenece a las relaciones que tiene una nación con otra; y en este sentido decimos: comercio INTERNACIONAL.

Recepción RAE: DRAE, 1852.

\section{internacional}

DERECHO INTERNACIONAL: DERECHO DE GENTES.

Recepción RAE: DRAE, 1914.

\section{involucrar}

[Neol] Met. Mezclar asuntos o especies inconexas. 


\section{jefatura $\circ$ jefatura política}

La dignidad o cargo de jefe superior político de una provincia.

Recepción RAE: DRAE, 1899.

\section{jefatura o jefatura política}

El edificio en el que están las oficinas de dicho jefe político.

\section{juego de bolsa $s$. $v$. juego}

El agiotaje en los fondos públicos.

Recepción RAE: $\varnothing$.

\section{jugar a la alza, s. v. jugar}

Obligarse a recibir cierta cantidad de papel de los fondos públicos, pagándolo entonces al cambio corriente del día en que se hace la obligación, con la esperanza de que ha de subir. Recepción RAE: DRAE, 1925.

\section{jugar a la baja, $s . v$. jugar}

Comprometerse el que espera que bajen los fondos públicos a entregar cierta cantidad de este papel en una época que se fija, recibiendo su valor al cambio que tenia el día que se firmó la obligación.

Recepción RAE: DRAE, 1925.

\section{jugar en la bolsa, $s . v$. jugar}

Especular con mucha frecuencia en los fondos públicos, bien comprándolos y vendiéndolos en realidad, bien obligándose a darlos o recibirlos en cierta época, en la que se pagan las diferencias que resultan en la variación de los cambios; que es el modo más común de hacer este juego.

Recepción RAE: $\varnothing$.

\section{jurado}

[Neol] Tribunal de origen inglés, introducido ya en otras naciones, cuyo cargo es determinar y declarar el hecho, que por las leyes corresponde al mismo. Llámase así también cada uno de los individuos que componen dicho tribunal.

Recepción RAE: DRAE, 1843.

\section{legitimista}

El partidario de la legitimidad rigurosa respecto de los que ocupan los tronos.

Recepción RAE: DRAE, 1884.

\section{liberal}

El que tiene ideas favorables a la justa libertad del pueblo.

Recepción RAE: DRAE, 1852.

\section{mano de obra, $s$. v. mano}

MANos, la hechura, el trabajo que se emplea en una obra.

Recepción RAE: DRAE, 1914. 


\section{manufacturar}

Fabricar artefactos, trabajar en manufacturas.

Recepción RAE: DRAE, 1925.

\section{mayoría}

El mayor número de los que componen una nación, ciudad, etc. o algún cuerpo moral; por ejemplo: la MAYORÍA de los artesanos lo repugna; ha votado con la MAYORÍA. Recepción RAE: DRAE, 1852.

\section{mayoría}

El partido que en un cuerpo deliberante reúne de ordinario el mayor número de votos; y en este sentido, se dice que el ministerio camina acorde con la mayoría de las cortes. Recepción RAE: DRAE, 1852.

\section{mayoría absoluta, s. v. mayoría}

La mitad más uno del número de votantes.

Recepción RAE: DRAE, 1869.

\section{melomanía}

Pasión por la música.

Recepción RAE: DRAE, 1899.

\section{melómano, na}

El que es loco por la música, el extremadamente aficionado a ella. Recepción RAE: DRAE, 1899.

\section{mensaje}

La comunicación oficial entre el poder ejecutivo y legislativo, o entre el congreso de diputados y el senado.

Recepción RAE: DRAE, 1884.

\section{mensajería}

Galera para transportar géneros, y también personas, de un punto a otro en días señalados, y en menos tiempo que los carros ordinarios.

Recepción RAE: DRAE, 1852.

\section{merino, na}

Tela delgada de lana, de que hacen hoy en día mucho uso las señoras para vestidos.

Recepción RAE: DRAE, 1869.

\section{mesa}

El presidente y los secretarios o escrutadores de algunas juntas o corporaciones. En este sentido se dice: tal partido ha ganado la MESA; la mesa votó con la minoría o la MESA estaba dividida.

Recepción RAE: DRAE, 1884. 


\section{metodizar}

Arreglar con el debido método, ordenar.

Recepción RAE: DRAE, 1869.

\section{ministerial}

El que es partidario del ministerio: se dice particularmente de los diputados y senadores que apoyan con sus discursos y sus votos las propuestas y sistema de los ministros. Recepción RAE: DRAE, 1869.

\section{minoría}

El número menor de los individuos de una nación, ciudad, etc. o de cualquier cuerpo moral; y en este sentido se dice: la MiNORÍA de los españoles estaba a su favor; su opinión no podía hallar cabida sino en una MINORÍA de cuatro o cinco votos de los doce que componían la junta. Recepción RAE: DRAE, 1852.

\section{minoría}

La parte menos numerosa de un cuerpo deliberante; que está de ordinario en oposición con la mayoría; y relativamente a ella se dice: la MINORía se ha reforzado con los dos diputados que acaban de llegar; la MINORÍA sigue haciendo una guerra cruda al ministerio. Recepción RAE: DRAE, 1852.

\section{modernizar}

Dar una forma moderna a lo que es antiguo.

Recepción RAE: DRAE, 1925.

\section{móvil}

Causa, motivo, autor; así decimos: el móvil de todo el alboroto ha sido un aguador. Recepción RAE: DRAE, 1884.

\section{municipal}

Concejal, regidor. Úsase más en plural hablando de todos los individuos que componen un concejo o ayuntamiento.

Recepción RAE: DRAE, 1852.

\section{nacionalidad}

El estado de los pueblos que forman una nación independiente.

Recepción RAE: DRAE, 1869.

\section{núcleo}

El punto céntrico de una cosa, así en lo físico como en lo moral.

Recepción RAE: DRAE, 1869.

\section{ómnibus}

Carruaje capaz de un gran número de personas, que las conduce de un punto a otro en las ciudades muy populosas, a horas determinadas y por un precio moderado.

Recepción RAE: $D R A E, 1852$. 
hacer la oposicion ó ser de la oposición, s. v. OPOSIClÓN

Pertenecer a la minoría de un cuerpo representativo.

Recepción RAE: DRAE, 1852.

\section{optimismo}

El sistema de los que sostienen que todo lo que sucede es bueno en sumo grado. Recepción RAE: DRAE, 1852.

\section{optimista}

El que sigue y defiende el optimismo.

Recepción RAE: DRAE, 1852.

\section{orgía}

Met. Comilona, borrachera. En una y otra acepción es más usado en plural.

Recepción RAE: DRAE, 1869.

\section{tener la palabra, $s . v$. palabra}

Tener permiso para hablar el individuo de un cuerpo o reunión, por haberlo obtenido de su presidente. Se dice también que TIENE LA PALABRA cuando está hablando.

Recepción RAE: DRAE, 1852.

\section{pañoleta}

Pañuelo pequeño que usan las mujeres para el cuello.

Recepción RAE: DRAE, 1852.

\section{papillota}

El papel en que envuelve el cabello para que tome rizo, y la carne, particularmente las costillas, para asarla, y que no se caiga el pan rallado y demás ingredientes que se le echan. Es voz tomada del francés.

Recepción RAE: $\varnothing$.

\section{parecer}

Salir a luz, publicarse un libro.

Recepción RAE: $\varnothing$.

\section{parlamentario, ria}

Lo que está revestido de la mesura, decoro, y reserva que deben guardar los que hablan en los parlamentos o congresos, y se conforma con las reglas prescritas para el buen orden de sus discusiones; y en tal sentido se dice: eso se opone al lenguaje PARLAMENTARIO; así lo ordenan las formas PARLAMENTARIAS.

Recepción RAE: $\varnothing$.

\section{partir}

Seguir hablando de una materia bajo algún supuesto; como: PARTAMOs de este principio. Recepción RAE: DRAE, 1884. 


\section{pastel}

Arreglo o composición con que se procura dejar contentos a todos los que tienen interés en un negocio.

Recepción RAE: DRAE, 1925.

\section{pastelear}

Manejarse de modo que se deje contentos a los que disputaban o litigaban sobre algún punto.

Recepción RAE: DRAE, 1884.

\section{patente}

El permiso que da anualmente el gobierno a todos los que se ocupan en algún ramo de comercio o industria, para que puedan ejercitarlo, si han satisfecho la cuota proporcional que se les asigna.

Recepción RAE: DRAE, 1925.

\section{pensión}

La casa en que se cuida de la educación de los muchachos, los cuales están A PENSIÓN ENTERA, cuando comen y duermen en ella; o A MEDIA PENSIÓN, si solo hacen una comida y se retiran a sus casas por la noche.

Recepción RAE: DRAE, 1925.

\section{perfectibilidad}

La cualidad de lo que admite mejora o perfección.

Recepción RAE: DRAE, 1914.

\section{perfectible}

Lo que puede recibir mejora o perfección.

Recepción RAE: DRAE, 1914.

\section{politipar}

V. Clisar.

Recepción RAE: $\varnothing$.

\section{poltrona}

SiLLA MiNisTERIAL.

Recepción RAE: $\varnothing$.

\section{positivo, va}

Lo que tiene una utilidad o ventaja real; $y$ en este sentido se dice: ahora no se busca mas que lo positivo.

Recepción RAE: DRAE, 1869.

\section{precedente}

Antecedente, EJEMPLAR.

Recepción RAE: DRAE, 1884. 


\section{prejuzgar}

[Neol] Juzgar de las cosas antes del tiempo oportuno, o sin tener en ellas cabal conocimiento.

Recepción RAE: DRAE, 1843.

\section{preopinante}

[Neol] Da este nombre el que está perorando en alguna junta u otra corporación, a cualquiera de los individuos que le han precedido en el uso de la palabra.

Recepción RAE: DRAE, 1843.

\section{proclama}

[Neol] Alocución hecha por algún magistrado o jefe.

Recepción RAE: DRAE, 1843.

\section{prominente}

Met. Lo más señalado, lo que más se distingue entre otras cosas, como: la más PROMINENTE entre sus virtudes era la caridad.

Recepción RAE: DRAE, 1992.

\section{proteo}

Met. Veleta, el que cambia de opiniones o vuelve casaca.

Recepción RAE: DRAE, 1899.

provisorio, ria

PROVISIONAL.

Recepción RAE: DRAE, 1985.

\section{pupitre}

Mueble que forma un plano inclinado; y sirve para poner en él un libro o algún papel de música, para leerlos más cómodamente; y más de ordinario para escribir.

Recepción RAE: DRAE, 1852.

\section{quinqué}

Velón que tiene el aceite en el cerco hueco que lo rodea, o en un receptáculo que lo despide por varios medios a proporción que se consume.

Recepción RAE: DRAE, 1884.

\section{rango}

Clase, jerarquía, calidad de las personas.

Recepción RAE: DMILE, 1927.

\section{redículo}

La bolsa en que las mujeres llevan el pañuelo, bolsillo, etc.

Recepción RAE: $\varnothing$. 


\section{reemplazar}

Llenar las bajas del ejército.

Recepción RAE: $\varnothing$.

\section{representativo, va}

Se aplica a la forma de gobierno en que varios diputados, elegidos por la nación, concurren a la formación de las leye.

Recepción RAE: $\varnothing$.

\section{revancha}

Desquite, despique.

Recepción RAE: DMILE, 1927.

\section{revancha}

Pago, correspondencia.

Recepción RAE: $\varnothing$.

\section{revancha}

La partida que se juega para que pueda desquitarse el que perdió.

Recepción RAE: $\varnothing$.

revolucionario, ria

[Neol.] Alborotador, turbulento.

Recepción RAE: DRAE, 1843.

\section{revolucionarse}

Rebelarse, sublevarse, amotinarse.

Recepción RAE: $D R A E, \varnothing$.

\section{ridículo, la}

Rediculo. La bolsa en que las mujeres llevan el pañuelo, bolsillo, etc.

Recepción RAE: $\varnothing$.

\section{romanticismo}

El sistema de los que se apartan, en las composiciones literarias, de las reglas seguidas por los clásicos griegos y latinos.

Recepción RAE: DRAE, 1852.

\section{romántico, ca}

Se aplica al escritor que sigue las doctrinas del romanticismo.

Recepción RAE: DRAE, 1852.

\section{romántico, ca}

$\mathrm{El}$ que en sus hábitos, porte, etc. se aparta de los demás.

Recepción RAE: DRAE, 1852. 


\section{satin}

Raso, tela de seda lustrosa.

Recepción RAE: DRAE, 1899.

\section{secatura}

Fam. Insulsez, fastidio

Recepción RAE: DRAE, 1843.

\section{sentimental}

Lo que excita afectos tiernos o la persona propensa a ellos.

Recepción RAE: DRAE, 1843.

\section{servil}

El que es poco amigo de las ideas liberales, y le gusta vivir bajo un gobierno despótico. Recepción RAE: DRAE, 1869.

\section{servilismo}

La predilección que alguno tiene, por naturaleza, interés o educación, a favor de las ideas, propias para mantener los gobiernos arbitrarios y despóticos.

Recepción RAE: DRAE, 1869.

\section{servilmente}

Con servilismo, de un modo servil.

Recepción RAE: $\varnothing$.

\section{sexcentista}

Nombre que se da a los escritores que florecieron en el siglo XVI.

Recepción RAE: $\varnothing$.

\section{sicofanta}

Engañador, embustero.

Recepción RAE: DRAE, 1780 (1899).

\section{sicofanta}

Adulador, lisonjero.

Recepción RAE: $\varnothing$.

\section{sinonimista}

El que se dedica al estudio de los sinónimos o escribe algún tratado acerca de ellos. Recepción RAE: $\varnothing$.

\section{sociablemente}

Francamente, amigablemente.

Recepción RAE: $\varnothing$. 


\section{sociedad en comandita, s. v. sociedad}

La que tiene la razón del que la administra, el cual es el único responsable, aunque está asociado con una o más personas que han puesto en ella algunos fondos.

Recepción RAE: DRAE, 1852.

\section{suficiencia}

Vanidad, aire de presunción.

Recepción RAE: DRAE, 1956.

\section{talmente}

Fam. De tal modo, de tal manera.

Recepción RAE: DRAE, 1925.

\section{tendencia}

Propensión o mira que se descubre en las acciones humanas hacia un fin, distinto a veces del que aparenta tener.

Recepción RAE: DRAE, 1869.

\section{terrorismo}

El sistema de terror que a que suele recurrirse en las convulsiones políticas.

Recepción RAE: DRAE, 1869.

\section{terrorista}

El que es inclinado al terrorismo o uno de sus agentes.

Recepción RAE: DRAE, 1884.

\section{textura}

La disposición y tejido de las parte que componen un cuerpo.

Recepción RAE: DRAE, 1899.

\section{tipo}

Letra de imprenta y el grado o carácter de ella.

Recepción RAE: DRAE, 1884.

\section{torno}

Máquina con que el mayoral de una diligencia sujeta desde su asiento las ruedas de la derecha, cuando se baja una cuesta.

Recepción RAE: DRAE, 1899.

\section{transacción}

P1 Negocios, tratos, convenios, etc., entre dos o más personas.

Recepción RAE: DRAE, 1852.

\section{transporte}

Arrebato, ímpetu, rapto de la razón.

Recepción RAE: DRAE, 1884. 


\section{turrón}

El provecho que para sí procuran sacar de un cambio político los que han tomado parte en él; y así se dice: ya van repartiéndose el ruRRón; a N. no le ha tocado lo peor del turrón. Recepción RAE: DRAE, 1884.

\section{útil}

Pl Utensilio de algún oficio o arte.

Recepción RAE: DRAE, 1869.

\section{utilizar}

APROVECHAR, emplear útilmente alguna cosa.

Recepción RAE: DRAE, 1852.

\section{valsar}

[Neol] Bailar el vals.

Recepción RAE: DRAE, 1843.

\section{versión}

Met. Sentido, interpretación que se da a alguna acción, suceso, etc., o el juicio que se forma de una cosa; y así se dice: no es esa la versión que corre sobre su retirada del ministerio. Recepción RAE: DMILE, 1852. 